\title{
MODELOS DE CONSTATAÇÃO DE PROVAS EM LIDES DE IMPROBIDADE ADMINISTRATIVA E CONFISCO ALARGADO NO PROCESSO PENAL
}

\author{
Standards of proof in administrative misconduct actions and assets forfeiture
}

\author{
MATEUS EDUARDO SIQUEIRA NUNES BERTONCINI ${ }^{1}$ \\ FÁBIO ANDRÉ GUARAGNI ${ }^{2}$ \\ GUSTAVO HENRIQUE ROCHA DE MACEDO ${ }^{3}$
}

\begin{abstract}
RESUMO
O ensaio afirma a descoberta da verdade como condição imprescindível para a efetividade da jurisdição, e, consequentemente, do Direito. Admitindo a impossibilidade de obtenção de verdade absoluta, apresentam-se os principais modelos de constatação de provas, relacionando critérios metodológicos para a eleição do standard mais adequado a cada tipo de processo. Como resultado, conclui-se que o modelo da probabilidade prevalente é o mais adequado para julgamento de ações de improbidade administrativa. Defende-se, por fim, que os mesmos argumentos levam à utilização do standard da probabilidade prevalente à perda de bens incompatível com o patrimônio do criminoso, recentemente incluída no Código Penal.
\end{abstract}

Palavras-chave: standards probatórios. Improbidade administrativa e confisco alargado. Probabilidade prevalente.

\footnotetext{
ABSTRACT

1 Mateus Eduardo Siqueira Nunes Bertoncini é Pós - Doutor em Direito pela Universidade Federal de Santa Catarina. Doutor e Mestre em Direito do Estado pela Universidade Federal do Paraná. Professor do Programa de Mestrado em Direito do Centro Universitário Curitiba (UNICURITIBA), ministrando a disciplina de Teoria da Empresa Social e Constituição brasileira. Leciona Direito Administrativo e Processo Administrativo em cursos de graduação e pós-graduação na Faculdade de Direito de Curitiba e na Fundação Escola do Ministério Público do Estado do Paraná.

2 Possui graduação em Direito pela Faculdade de Direito de Curitiba (1992), graduação em Administração de Empresas pela Universidade Federal do Paraná (1991), Mestrado em Direito pela Universidade Federal do Paraná (1998) e Doutorado em Direito das Relações Sociais, com ênfase em Direito Penal, pela Universidade Federal do Paraná (2002). Realizou pesquisa Pós-Doutoral na Università degli Studi di Milano (2012). Atualmente é professor titular do Centro Universitário Curitiba - UNICURITIBA, professor da Escola da Magistratura do Paraná - EMAP e professor da Fundação Escola do Ministério Público do Paraná - FEMPAR.

${ }^{3}$ Promotor de Justiça no Estado do Paraná. Mestrando em Direito Empresarial e Cidadania no Centro Universitário Curitiba - UNICURITIBA.
} 
The article claims that the discovery of truth as an indispensable condition for the effectiveness of jurisdiction, and consequently of law. Assuming the impossibility of obtaining absolute truth, it presents the main standards of verification, relating methodological criteria for the election of the most appropriate standard for each type of process. As a result, it remains that preponderance of evidence is the standard that best fits for judging administrative misconduct actions. Finally, it is argued that the same arguments lead to the use of the standard of evidence prevailing for the loss of property incompatible with the criminal's assets, recently included in criminal law.

Key-words. Standards of proof. administrative misconduct actions and asset forfeiture. Preponderance of evidence.

\section{INTRODUÇÃO}

A atividade probatória no âmbito das relações processuais tem como finalidade a apuração da verdade, pressuposto para o exercício da jurisdição. Afinal, a legitimidade das decisões judiciais pode ser defendida com maior propriedade na medida em que o Judiciário não se restrinja a resolver o processo, como se fosse um fim em si próprio, mas aplique a norma adequada ao suporte fático correspondente à verdade.

A identificação dos fenômenos da vida e sua posterior representação no palco da relação processual não é simples. Razões concretas e filosóficas, entre outras, tornam essa (re)construção tormentosa, ensejando controvérsias sobre seus limites (é possível descobrir a verdade?; o que é verdade?). É nesse terreno movediço que se interpreta o Direito positivo, quando pretende disciplinar a produção da prova no processo, estabelecendo regras sobre ônus e restrições, assim como critérios de valoração (apreciação judicial ou legal).

Para além desses aspectos, há o debate acerca dos modelos de verificação das provas. Discutem-se os standards probatórios, que em outras palavras, são métodos para se averiguar se esta ou aquela alegação está satisfatoriamente comprovada pelo conjunto de provas.

O objetivo desse texto é mostrar um breve resumo dos modelos aventados pela doutrina, e então se submetê-los a testes para responder-se à indagação sobre qual o mais adequado nos processos nos quais se controverte acerca da prática de atos de improbidade administrativa, assim como para decretação da nova modalidade de perda de bens recentemente incluída no art. 91-A do Código Penal.

Também serão analisados precedentes e escólios doutrinários que trataram do tema, e se buscarão paralelos no Direito comparado para se dar suporte ao resultado obtido ao final da pesquisa 


\section{JURISDIÇÃO, INTERPRETAÇÃO E A BUSCA DA VERDADE}

Numa breve síntese, pode-se afirmar que a principal função do processo é “impor uma disciplina que constitui a principal garantia para o correto exercício do poder" (GOMES FILHO, 2014). O processo é o instrumento utilizado pela jurisdição para a descoberta dos acontecimentos e definição de qual a norma regente de determinada relação jurídica, mediante substituição da vontade das partes.

O início do trabalho decisório não é outro que não a identificação da realidade, é dizer, se aconteceu a hipótese prevista por uma norma, que acarreta a aplicação de sua consequência. Afinal, "as normas jurídicas estabelecem os contornos fáticos e os seus sucessivos desdobramentos e, por isso, hospedam hipótese (prótase) e consequência (apódose)” (ROCHA, 2016, p. 92/93). Dessa maneira, não se pode conceber que a jurisdição atuou satisfatoriamente se aplicou o Direito a um fato não verdadeiro, ou ainda, se deixou de impor determinada consequência a uma hipótese por falhar na verificação de seu acontecimento.

A jurisdição, assim, tem como objetivo fundamental a justa composição da lide, mediante atuação da vontade concreta do Direito, finalidade cuja satisfação pressupõe a apuração da verdade sobre os fatos subjacentes à controvérsia. Nesse trabalho, a identificação do suporte fático concreto e imposição da consequência abstratamente prevista na norma não se resume a um movimento de mão única, e, mais ainda, de algo que possa prescindir da atribuição de valores por parte do juiz, tanto na análise do fato, quanto na interpretação da norma.

Superando os paradigmas do silogismo e da espiral hermenêutica, Taruffo (2017, p. 88) propõe um novo modelo para a conexão entre fato e norma. Chama-o de trial and error, ou abdução e verificação:

\footnotetext{
Esse modelo tem como aspecto essencial o controle hipotético, e pode articular-se em uma cadeia mais ou menos longa de passos: uma hipótese relativa ao fato se controla mediante uma hipótese sobre o significado da norma que aquele fato se refere; por sua vez, a hipótese sobre o significado da norma se verifica com base na hipótese sobre o fato. Essas hipóteses modificam-se de tempos em tempos com base na verificação, e o procedimento continua descartando todas as hipóteses que cada vez não são confirmadas, até que se chegue a uma hipótese de fato que corresponde à prótase da norma interpretada em uma determinada hipótese. Trata-se do momento no qual o fato pode ser subsumido na norma, que resulta interpretada com base no fato e, portanto, pode ser aplicada a ele.
}

Daí se pode concluir que o fato é o marco inicial do processo interpretativo, que acontece em fluxo contínuo de cotejos de hipóteses sobre ele (o fato) e sobre a norma. A 
vantagem dessa proposta é dar destaque à realidade, realçando o condicionamento mútuo entre fato e norma.

Qualquer que seja o modelo (silogismo, espiral hermenêutica ou abdução e verificação), pressupõe-se a identificação do fato, que é evento aperfeiçoado fora e, em regra, anteriormente ao processo; é nele introduzido pelas narrações das partes e demais personagens $(\text { como testemunhas e peritos })^{2}$, que conduzem à última das narrativas: a judicial, dotada de status epistêmico de verdade (TARUFFO, 2018, p. 6). Com efeito, a sentença não escolhe a melhor ou a pior das narrativas, mas aquela que se submete à confirmação probatória, visto que o processo não é um concurso literário destinado à escolha do melhor romance.

Aqui se deve enfatizar que a verdade é um "predicado de um enunciado que afirma alguma coisa a respeito de um fato" (TARUFFO, 2017, p. 185). Dito de outra forma, a verdade seria a correspondência entre uma narração e a realidade. É nesse espaço de confirmação que se discute sobre os limites e as possibilidades de comprovação, porque a exata reconstrução de um evento é algo inatingível, porque "as provas não têm a aptidão para conduzir seguramente à verdade sobre o fato ocorrido, apenas mostram elementos de como, provavelmente, o fato ocorreu" (MARINONI e ARENHART, 2005, p. 64):

Tal impossibilidade decorre de sucessivas distorções inerentes ao processo de conhecimento dos objetos, realizado pelos sujeitos. Embora não se negue a existência de uma realidade, a verdade é atributo que se coloca a respeito de uma afirmação sobre algo que se passou. Assim, cada indivíduo que narra um fato à sua descrição aplica tintas de suas impressões pessoais. Dessa forma, haverá tantas versões quantas forem as narrativas.

No plano processual, as limitações são ainda maiores, pois às subjetividades acrescidas pelos sujeitos em suas respectivas leituras se acrescem outras circunstâncias, como limitações na produção das provas, falhas na identificação, além da possibilidade de se negar a verdade, esta última por vezes lastreada na confiança de que não haverá prova sobre a autenticidade do que sustenta a parte adversa. Tal processo, em que há sucessivas construções de hipóteses sobre o fato e a norma, é traduzido em abdução e verificação, encerrando-se com o julgamento, em que a norma é aplicada à hipótese factual comprovada.

É cogente admitir-se que o processo se rege por verdade relativa, ou seja, a mais aproximada possível da realidade. Essa relatividade, porém, não está atrelada a um paradigma

\footnotetext{
${ }^{2}$ Por exemplo, os fatos constitutivos do direito do autor, ou os extintivos, modificativos e impeditivos alegados pelo réu (art. 373, do Código de Processo Civil). No processo penal, os fatos não são apenas a conduta e a sua tipicidade, mas também eventuais excludentes de ilicitude, dirimentes de culpabilidade, escusas absolutórias, atenuantes ou causas de privilégio. Por isso a afirmação de que os fatos são apresentados pelas partes, não só pelo autor.
} 
subjetivo; pelo contrário, a relatividade da verdade alcançada no processo tem parâmetros objetivos "para indicar que a proposição fatual de que se trata é verdadeira em relação à quantidade e à qualidade das informações que a confirmam.” (TARUFFO, 2017, p. 195)

É necessário, então, o desenvolvimento de técnicas de análise das provas, no afã de se parametrizar o exercício jurisdicional na apreciação da suficiência daquilo que se reuniu na instrução. É o que se chama de modelos de constatação, ou standards probatórios.

\section{MODELOS DE CONSTATAÇÃO: FATORES POLÍTICOS PARA ESCOLHA}

A impossibilidade prática de se reconstruir a realidade e, consequentemente, atingirse a verdade absoluta, exige a eleição de modelos de constatação da suficiência probatória. A descoberta (ainda que aproximada) da verdade é imprescindível para se aplicar a lei ao caso concreto, sob pena de se resolverem controvérsias a partir de premissas falsas, o que levaria ao desvirtuamento do Direito. De tal forma, a definição dos standards probatórios visa a distribuir entre as partes do processo os riscos do erro.

A escolha do método de constatação situa-se, então, no plano político. Se o legislador define que num determinado tipo de processo há limites na produção de provas, e que estas devem ser absolutamente seguras para que o juiz considere uma afirmação como comprovada, haverá naturalmente maior número de pretensões julgadas improcedentes. Por outro lado, se o rigor probatório for menor, a tendência é de aumento no número de sentenças de procedência.

A consequência prática entre essas escolhas é mais claramente perceptível no processo penal. Quanto maior a exigência de provas, maior será o número de absolvições, o que significa que se diminui a chance de se condenarem inocentes; por outro lado, aumentam-se as possibilidades de se absolverem culpados (FERRER BELTRÁN e TUZET, 2018³).

A distribuição dos riscos deve ser orientada, essencialmente, por três fatores entrelaçados: os custos de falsas absolvições; a magnitude do bem jurídico; e a dificuldade na demonstração da verdade.

\footnotetext{
${ }^{3}$ No original: “Così, per esempio, se alziamo la soglia di sufficienza probatoria nel processo penale avremo meno innocenti condannati (posto che sarà più difficile che si acquisisca contro di loro um insieme probatorio incriminatore di tale livello), ma avremo più colpevoli assolti (dato che, anche rispetto ai soggetti che effettivamente hanno commesso i fatti che vengono loro imputati, sarà più difficile soddisfare le esigenze probatorie richieste dallo standard). In senso opposto, se abbassiamo il livello di sufficienza probatória dello standard, è prevedibile che avremo meno colpevoli assolti (perché sarà più facile reperire prove di colpevolezza che permettano di raggiungere tale livello di sufficienza), ma più innocenti condannati (perché, anche rispetto a loro, sarà più facile superare il grado di corroborazione richiesto)".
} 
3a) No que toca aos custos, a escolha da sociedade sobre o nível de suficiência de provas a respeito de uma pretensão está diretamente relacionada aos riscos que ela aceita de que ela (a pretensão), malgrado justa, não seja acolhida pelo Judiciário.

A tendência inicial, num dilema desse tipo, normalmente se inclina à preferência pela primeira opção. É que a possibilidade de se condenar um inocente se revela chocante. A propósito, atribui-se a Voltaire o pensamento de que "é melhor correr o risco de salvar um homem culpado do que condenar um inocente”, inspiração básica do adágio in dubio pro reo.

O problema é que rigores excessivos, insuscetíveis de observância na praxe, podem ocasionar o indesejável efeito colateral de se desacreditar o sistema de justiça e, por conseguinte, o próprio ordenamento. Se a única preocupação fosse evitar qualquer possibilidade de condenações de inocentes, bastaria que fosse proibida qualquer condenação.

Porém, isso produziria cenário de proteção deficiente. Com efeito, uma das obrigações do Estado é a de tutelar os direitos dos cidadãos. Esse ângulo é observado por Moro (2014, p. 559/560), quando discorre sobre direitos fundamentais contra o crime:

\footnotetext{
Outras normas constitucionais, apenas de não conterem mandados de criminalização, podem ser interpretadas de forma a outorgar ao cidadão uma proteção contra o crime. Uma delas, a garantia de proteção judiciária prevista no inciso XXXV do art. $5^{\circ}$ da Constituição Federal. Na interpretação clássica, ela garante ao cidadão a tutela jurisdicional efetiva contra lesão ou ameaça de lesão a direito. No âmbito do processo penal, pode ser invocada tanto para a proteção do investigado ou acusado contra abusos investigatórios ou persecutórios, como também para a proteção e a tutela dos direitos da vítima lesionados ou ameaçados pelo crime.
}

Desenvolvendo-se essa linha, desponta que legislação protetiva de direitos tornar-seia inócua se o nível de demonstração do suporte fático concreto resultasse inatingível. Reiteradas absolvições de autores de crimes também não seriam resultados desejáveis, já que deixariam às vítimas sem qualquer proteção. No processo civil, o mesmo ocorreria, já que a elevação excessiva do nível de exigência tornaria inviável a demonstração da procedência dos pedidos, e teria por efeito mediato o estímulo à inadimplência das obrigações (legais ou contratuais).

A escolha do modelo de verificação necessita ponderar tais aspectos, permitindo conciliar essa dupla face da segurança jurídica, que impeça injustiças de lado a lado, ou seja, evitando, na maior medida possível, tanto as falsas condenações quanto as falsas absolvições.

3b) O segundo elemento cuja análise é reivindicada na escolha de um modelo de verificação é a natureza do direito material subjacente à relação processual. Ou seja, o rigor probatório é diretamente proporcional à gravidade da consequência passível de imposição pelo 
juiz. Com esse enfoque, a doutrina mais ortodoxa pregava a distinção entre a apuração da verdade no processo penal e no processo civil: enquanto naquele se buscava a verdade material $^{4}$, neste bastaria a verdade formal ${ }^{5}$.

A dicotomia verdade material/verdade formal não parece sustentável, na medida em que não se pode afirmar, a priori, que o processo penal sempre trate de temas mais elevados do que o processo civil. A base da separação era a afirmação de que a liberdade do indivíduo estaria em jogo no primeiro, ao passo em que tradicionalmente o segundo cuidaria de demandas patrimoniais.

Essa premissa é facilmente infirmada, porque hoje há no Direito Penal penas não privativas de liberdade. Para não se falar em penas substitutivas, cujo descumprimento pode resultar na conversão em pena corporal (salvo a multa), basta recordar das sanções estatuídas no preceito secundário do art. 28 da Lei Federal n 11.343/2006, e das sanções restritivas de direitos passíveis de imposição a pessoas jurídicas como respostas a crimes ambientais (Lei Federal nº 9.605/98, art. 22).

A isso se acresce que há muito tempo o processo civil não se dedica apenas a satisfação de obrigações patrimoniais, valendo mencionar lides a respeito de extinção do poder familiar e guarda de filhos, adoção, tutela do direito à saúde, internações compulsórias. Esses são apenas alguns exemplos de objetos litigiosos, controvertidos no processo civil, cuja estatura é indiscutivelmente superior às restrições ilustradas no parágrafo anterior. Com efeito, ninguém duvida que a extinção do poder familiar é consequência muito mais severa que a prestação de serviços a comunidade.

Conquanto não se possa mais afirmar a existência de verdade formal e de verdade material, isso não significa vedação à adoção de diferentes modelos de constatação no processo civil e no processo penal. Baltazar Junior (2007, p. 179) explica não ser possível negar que “em razão do influxo do direito material em jogo, bem como dos princípios do in dubio pro reo e da própria noção de culpabilidade, há conseqüências no campo probatório, que consistem justamente na adoção de diferentes standards ou modelos de constatação para o processo civil e o penal."

\footnotetext{
${ }^{4}$ FREDERICO MARQUES (2000, v. II, p. 337) defendia que " a verdade real - eis a causa finalis da instrução e, portanto, do próprio processo. Tendo em vista os graves interesses que estão em conflito, na instância penal, é absolutamente imprescindivel que fique elucidado o thema probandum a fim de que se dê solução justa e exata ao pedido que se contém na acusação."

${ }^{5}$ Comentando o art. 332, do Código de Processo Civil de 1973, NERY JUNIOR e ANDRADE NERY (2001, p. 818) expunham que "o Sistema processual admite, para o julgamento, a verdade formal, salvo os casos de direito indisponível, como já se disse, ou daqueles em que se exige prova legal, cuja valoração o legislador prefixa." A orientação é reafirmada nos Comentários ao Código de Processo Civil-Novo CPC-Lei 13.105/2015, p. 984.
} 
3c) O terceiro fator que se entrelaça aos dois primeiros (custos das falsas absolvições e magnitude do bem jurídico) na escolha político-moral do standard probatório tem a ver com a dificuldade da obtenção de provas em determinados casos. Ferrer Beltrán e Tuzet (2018, p. 461) trazem como exemplos os delitos sexuais e o crime de corrupção. Quanto ao último, afirmam que

\begin{abstract}
Se encontram consideráveis dificuldades para seguir o movimento do dinheiro (muitas vezes entre contas de diversos países, especialmente paraísos fiscais, com pessoas interpostas) para correlacionar, por exemplo, tais movimentações econômicas com o pagamento de decisões políticas. Em casos desse tipo, as dificuldades probatórias dão razão para a diminuição do nível de suficiência do standard, para evitar a impunidade e, como isso, que a figura do crime se torne inútil porque inaplicável ${ }^{6}$.
\end{abstract}

Apesar do anunciado risco de impunidade, o standard não pode ser tão reduzido a ponto de, especificamente no processo penal, permitir a irrupção de responsabilidade objetiva. Aqui são oportunas as reflexões de Moro (2010, p. 72), ao tratar da prova do elemento subjetivo do crime de lavagem de dinheiro. Após mencionar documentos internacionais, em especial a recomendação "2.b” da Financial Action Task Force ("A intenção e o conhecimento exigidos para provar o crime de lavagem de dinheiro é consistente com os parâmetros traçados nas Convenções de Viena e Palermo, incluindo o conceito de que o estado mental pode ser inferido de circunstâncias fáticas objetivas "), o doutrinador adverte que a diretiva não é absoluta e não retira do Ministério Público o ônus de comprovar os elementos cognitivo e volitivo do dolo. Caso contrário, haveria o risco de se condenar alguém com a razoável dúvida de que agisse em erro de tipo. No entanto, circunstâncias objetivas que demonstrem que seria impossível que o agente desconhecesse a conduta de branqueamento de capital autorizam a incidência da recomendação da FATF:

\begin{abstract}
Interpretada dessa maneira, a regra é válida e compatível com as exigências de um Direito Penal liberal-democrático, segundo o qual deve prevalecer o princípio de que, em casos criminais, exige-se prova acima de qualquer dúvida razoável do elemento objetivo e subjetivo. Portanto, dependendo do caso, da prova dos elementos e circunstâncias objetivas do crime de lavagem, poder-se-á concluir pela presença do elemento subjetivo.
\end{abstract}

\footnotetext{
${ }^{6}$ No original: "Un altro esempio chiaro di questo tipo di problema si incontra nei delitti di corruzione, dove si affrontano considerevoli difficoltà per seguire il movimento del denaro (molte volte tra conti di diversi paesi, specialmente di paradisi fiscali, com persone interposte, ecc.) al fine di correlare, ad esempio, tali disposizioni economiche con il pagamento di decisioni politiche ecc. In casi di questo tipo, le difficoltà probatorie operano da ragione per la diminuzione del livello di sufficienza dello standard, così da evitare l'impunità e, con ciò, che la figura di reato divenga inutile perché inapplicabile."

7 A FATF/GAFI é um organismo internacional cujos objetivos são definir modelos e promover efetivas implementações legais de medidas destinadas ao combate da lavagem de dinheiro, financiamento do terrorismo e outras ameaças à integridade do sistema financeiro internacional.
} 
Modelo perfeito não há, sendo todos passíveis de evolução dirigida à maior aproximação possível da verdade. A despeito de suas limitações, no atual estado da arte os standards mais densos são os que, na esfera penal, requer a prova acima de dúvida razoável (excetuados os crimes não punidos com prisão), e, no processo civil, que define a probabilidade prevalente.

\section{STANDARDS PRINCIPAIS: PROVA ACIMA DE DÚVIDA RAZOÁVEL, PROBABILIDADE PREVALENTE E PROVA CLARA E CONVINCENTE}

A partir desses eixos, foram desenvolvidos modelos de constatação da prova. Knijnik (2001, p. 27), em extensa e profunda pesquisa, arrola uma série de standards trabalhados em vários sistemas de justiça, mencionando

\footnotetext{
“' a evidence beyond a reasonable doubt', a 'preponderance of evidence', as 'special rules' (v.g. 'clear and convincing evidences'), a 'mínima atividade probatória', o modelo das dúvidas positivo-concretas, a 'doutrina do absurdo' e da 'arbitrariedade, a 'congruência narrativa', o 'défaut de motifs', os modelos matemáticosprobabilísticos."
}

Considerados os limites deste ensaio, serão tratados os três mais consagrados, quais sejam, o da prova acima de qualquer dúvida razoável, da probabilidade prevalente e da prova clara e convincente.

Do direito de matriz anglo-saxã vem a noção de que, no processo criminal, só se pode impor condenação se houver prova acima de dúvida razoável (proof beyond any reasonable doubt). Tal modelo de verificação, embora admita a possibilidade do erro (reconhece a relatividade da verdade obtida), reclama alto índice de credibilidade nas provas produzidas, para o fim de se afastar a presunção de inocência do cidadão.

O modelo de constatação proof beyond any reasonable doubt parece o mais apropriado quando se trata de processo cuja consequência pode ser a privação da liberdade. Excetuada a pena de morte possível no caso de guerra externa, tirar a liberdade de alguém é o ato mais grave que o Estado brasileiro pode praticar para punir um cidadão. É por isso que o risco de erro deve ser mínimo e, havendo dúvida sobre conduta e tipicidade, o caminho da absolvição é o correto. Registra-se que o standard é compatível com o sistema nacional (designadamente com os 
incisos II, V e VII, do art. 386, do Código de Processo Penal), tanto que vem sendo expressamente proclamado pelos Tribunais Superiores no julgamento de casos criminais ${ }^{8}$.

O instituto, porém, suscita críticas.

A primeira decorre de algo há pouco afirmado: o processo penal não trata mais exclusivamente sobre o bem jurídico liberdade (também afeta patrimônio e direitos políticos, para dizer o menos), donde resulta insustentável a existência de standard único. Como nem todos os processos penais têm como objeto a disputa pela liberdade, não se encontra justificativa para afirmar-se que em toda e qualquer lide dessa natureza se exija a prova acima de qualquer dúvida razoável, pois atualmente há penas semelhantes a consequências passíveis de imposição no processo civil e, porque não, em processos administrativos. Em termos práticos, a interdição temporária de estabelecimento imposta a uma empresa, pela prática de um crime ambiental, é exatamente a mesma coisa que um eventual embargo imposto por autoridade administrativa no exercício do poder de polícia.

Outra crítica frequente ao método b.a.r.d. é a manutenção de uma zona de incerteza sobre o que seria a dúvida razoável. Há algumas iniciativas matemáticas, como sugerir que seria algo como "menos de 95\% provado"; porém, Taruffo adverte com absoluto acerto que se trata de tentativas inúteis e absurdas de se quantificar o nível de prova necessário para evitar a dúvida razoável, ou de quantificar a própria dúvida razoável, porque se "fundam em alguma ideia de “alta probabilidade” da culpabilidade ou mesmo sobre o nível de tolerabilidade do erro ínsito no condenar um inocente frente à eventualidade de absolver um certo número de culpados".

Ele próprio admite a utilidade do standard, todavia, busca justificá-lo em termos qualitativos:

\footnotetext{
Uma proposta interessante a esse respeito é no sentido de que se tem uma dúvida razoável, em face de uma hipótese de culpabilidade que resulte provada, se contudo é possível formular uma outra hipótese plausível que explique os mesmos fatos que resultaram comprovados, mas compatíveis com a inocência do acusado. Esta proposta evita qualquer quantificação arbitrária e permite que se atribua um significado razoável à expressão "dúvida razoável”, impedindo a condenação quando a inocência do acusado não possa excluir-se com base nos fatos que foram provados.
}

\footnotetext{
8 "PENAL. PROCESSUAL PENAL. OPERAÇÃO SANGUESSUGA. DEPUTADO FEDERAL. QUADRILHA, CORRUPÇÃO PASSIVA E CRIME LICITATÓRIO DO ART. 90 DA LEI 8.666/93. COLABORAÇÃO PREMIADA. AUSÊNCIA DE CORROBORAÇÃO. INSUFICIÊNCIA DE PROVA ACIMA DE DÚVIDA RAZOÁVEL. PRESUNÇÃO DE INOCÊNCIA. ABSOLVIÇÃO.(...)" (STF, AP 676, Relator(a): Min. ROSA WEBER, Primeira Turma, julgado em 17/10/2017, ACÓRDÃ̃ ELETRÔNICO DJe-021 DIVULG 05-02-2018 PUBLIC 06-02-2018). No mesmo sentido: STF, AP 694, Relator(a): Min. ROSA WEBER, Primeira Turma, julgado em 02/05/2017, ACÓRDÃO ELETRÔNICO DJe-195 DIVULG 30-08-2017 PUBLIC 31-08-2017; STF, AP 580, Relator(a): Min. ROSA WEBER, Primeira Turma, julgado em 13/12/2016, ACÓRDÃO ELETRÔNICO DJe-139 DIVULG 23-06-2017 PUBLIC 26-06-2017; STJ, APn 593/MT, Rel. Ministro HUMBERTO MARTINS, CORTE ESPECIAL, julgado em 17/12/2012, DJe 07/02/2013.
} 
O autor parece ter recorrido a uma interpretação a contrario sensu do princípio do terceiro excluído para aferição da dúvida razoável. Esse parâmetro, nos dizeres de Ferrer Beltrán e Tuzet, significa que "uma vez reconhecido que em um dado âmbito se dão apenas duas alternativas ("tertium non datur"), a demonstração de falsidade de uma prova a verdade da outra" ". É que a dúvida razoável ocorreria com o atingimento, no fim do processo, de duas hipóteses plausíveis sobre o mesmo fato comprovado (v.g., o autor dos disparos pode ser A ou B).

No processo civil, outras possibilidades têm sido aventadas. O modelo da probabilidade prevalente ou mais provável que sim do que não tem sido bastante aclamado, e significa que "se as provas dos autos permitem concluir que a versão da parte autora é mais provável que a versão contrária, o juiz está autorizado a definir o juízo de fato nesse sentido" (CARPES, 2017).

O modelo é nomeado por Taruffo como o standard racional. Explica que inferências podem, com grau não absoluto de segurança, confirmar certa hipótese, e então "esta hipótese é preferida se tem um grau de confirmação probatória mais elevado do que o da hipótese contrária” (TARUFFO, 2017, p. 198).

Assim, ao se dar crédito à hipótese com maior prova do que a oposta, o sistema più probabile che non por certo amplia a chance da descoberta da verdade. A racionalidade aqui é lógica, pois a narrativa mais encorpada deve prevalecer sobre aquela suportada por elementos mais fracos. A versão mais provável, ou seja, com maior confirmação probatória, tem maior verossimilhança, e por tal razão deve ser admitida na sentença como verdadeira.

Ferrer Beltrán e Tuzet trabalham um standard intermediário, oriundo da jurisprudência americana, que reclama a chamada prova clara e convincente, não tão rigoroso quanto aquele que exige prova acima de dúvida razoável, nem tão flexível quanto o da hipótese mais provável. Entretanto, o modelo de verificação, ao exigir um caráter persuasivo da prova, deixa um flanco aberto ao arbítrio judicial. Eles próprios admitem que "tal standard intermediário tem um ponto fraco: sua formulação reclama o requisito subjetivo da convicção do julgador, o que arrisca transformá-lo em um exercício de introspecção que pouco tem a ver com a exigência epistemológica da reconstrução fatual" (FERRER BELTRÁN; Tuzet, 2018, p. 19). Ou seja, esse standard parece não atender completamente ao reclamo de controle intersubjetivo. $\mathrm{O}$ defeito revela que essa teoria pouco avança com relação ao critério da probabilidade prevalente,

\footnotetext{
9 No original: "una volta riconosciuto che in un dato ambito si danno due sole alternative ("datur"), la dimostrazione della falsità dell'una prova tertium non la verità dell'altra."
} 
crendo-se, com o devido respeito, que se trata de um argumento retórico não justificável: deveras, uma prova clara e convincente nada mais faz do que tornar uma hipótese mais provável que a hipótese oposta.

\section{A AÇÃO DE IMPROBIDADE E O STANDARD ADEQUADO}

Afirmou-se que a definição do modelo de verificação se situa no plano político, o que, em linha de princípio, exigiria decisão no plano legislativo. Entretanto, ausente escolha expressa na lei, não fica o juiz autorizado a escolher algum standard de maneira arbitrária. $\mathrm{O}$ caso reclamará a identificação de standard objetivo, extraível do sistema. Em qualquer caso, não se deve olvidar que a escolha do modelo passa pela calibragem dos fatores já externados, quais sejam, os custos das falsas absolvições ou condenações, o bem jurídico em litígio e a dificuldade prática na obtenção de provas.

O Código de Processo Civil brasileiro não se refere expressamente a um modelo de constatação, tampouco o faz a Lei Federal no 8.429/92, que prevê a punição aos atos de improbidade administrativo causadores de enriquecimento ilícito, prejuízo ao erário e violação aos princípios da administração pública.

Na jurisprudência do Tribunal de Justiça do Paraná, há clara tendência em se utilizar o modelo de constatação que proclama a necessidade de prova acima de dúvida razoável, a despeito de ação de improbidade não se confundir com processo penal.

A Corte Estadual aplicou esse rigor na admissibilidade da ação proposta pelo Ministério Público, dando provimento a agravo de instrumento sob o fundamento que " $a$ Colaboração premiada, por força da lei, é prova, porém, meramente indiciária, porque se não corroborada por outras provas seguras, que estejam além da dúvida razoável, não vale para o fim da condenação" (5 ${ }^{\text {a }}$ C.Cível - 0031610-04.2019.8.16.0000 - Londrina - Rel.: Desembargador Nilson Mizuta - J. 22.10.2019).

Em outro caso, desta feita em apelação, a $4^{\mathrm{a}}$ Câmara Cível julgou improcedentes os pedidos do Ministério Público, assentando que "não há nos autos, prova segura suficiente para impor à requerida a condenação por prática de ato de improbidade administrativa, pois apesar de incontroversas as irregularidades apontadas, remanesce, dúvida razoável sobre a efetiva autoria das irregularidades tais como narradas" (4ª C.Cível - AC - 1505843-6 - Paranavaí Rel.: Desembargadora Regina Afonso Portes - Unânime - J. 23.08.2016).

$\mathrm{Na}$ doutrina, há quem afirme o mesmo. É o caso de Lucon, que também sugere a adoção do mesmo standard do processo penal ao dizer que "consagra-se a vigência do 
princípio in dubio pro reo no âmbito da improbidade administrativa", embora adiante flexibilize sua afirmação, acenando para a aplicação do standard da prova clara e convincente: “quando menos, o standard de prova deve corresponder à "prova clara e convincente", pelo qual "a parte tem dever de convencer o julgador de que sua proposição é altamente provável, mais do que simplesmente "mais provável” que não." A última linha de entendimento é também defendida por Cambi (2018), que apregoa que o modelo de constatação apropriado nas ações de improbidade administrativa é o da prova clara e convincente.

Ainda na doutrina, mostra-se interessante o escólio de Knijnik (2001, p. 27), ao sustentar que o modelo da prova acima de dúvida razoável não se aplica fora de processos criminais, ainda que o fato que integra a causa de pedir também encontre tipificação como delito:

\footnotetext{
Um dado interessante é que o modelo da evidence beyond a reasonable doubt não deve ser utilizado em casos não-criminais, ainda que o fato nele versado seja um delito, ou seja, quando houver multi-incidência. "Quando uma acusação de crime está em causa numa ação cível, as consequências ameaçadoras (...) desta acusação, embora incomumente prejudiciais (...) não são tão sérias quanto num processo criminal pelo crime". Então, dever-se-á, ainda aqui, usar o standard civil ou o intermediário, conforme o caso, mas não o mais rigoroso, próprio dos casos criminais.
}

A transcrição acima não é supérflua, sobretudo porque há uma constelação de condutas que simultaneamente se qualificam como crime e como ato de improbidade administrativa. $\mathrm{O}$ exemplo mais nítido é da apropriação ilícita de valores cuja posse esteja com o funcionário público em razão do cargo: tal comportamento corresponde ao crime de peculato (art. 312, do Código Penal), e a ato de improbidade causador de enriquecimento ilícito (art. $9^{\circ}$, inciso XI, da LIA). Com esse cenário, a tese de Knijnik é a de que, no processo penal, aplica-se o standard da prova acima de dúvida razoável, ao passo que no processo civil se utilizaria outro modelo, menos exigente.

Com a observação de que o standard da prova clara e convincente pouco - ou nada difere da probabilidade prevalente (conforme crítica construída no tópico anterior), a última das posições mostra mais densidade, na medida em que o catálogo de penas dos artigos $6^{\circ}$ e 12 da Lei Federal $n^{\circ} 8.429 / 92$ é composto pela perda de bens ilicitamente acrescidos a seu patrimônio, perda da função pública, suspensão dos direitos políticos, multa civil e proibição de contratar com o Poder Público ou receber benefícios ou incentivos fiscais ou creditícios, direta ou indiretamente, ainda que por intermédio de pessoa jurídica da qual seja sócio majoritário. Não afetam, então, liberdade do indivíduo. 
Alvos de alguma controvérsia inicial, referidas sanções previstas tiveram sua natureza civil reconhecida pelo Supremo Tribunal Federal, especialmente no julgamento da ADI 2.797, de relatoria do Min. Sepúlveda Pertence (Tribunal Pleno, julgado em 15/9/2005, DJ $19 / 12 / 2006)^{10}$.

A explicitação da natureza civil desse tipo de resposta do ordenamento se mostra fundamental porque, como visto na doutrina de Ferrer Beltrán e Tuzet, os vetores que orientam a definição do modelo de constatação da prova são o bem jurídico em disputa, a dificuldade de produção da prova e os custos das falsas absolvições.

Não se cogitando, na ação de improbidade, da privação de liberdade, é manifestamente excessivo o método beyond any reasonable doubt. Afinal, não há diferença ontológica entre a multa prevista pela Lei Federal no 8.429/92 e uma cláusula penal de um contrato, porque ambas, se forem de igual valor, impactam o patrimônio do devedor da mesma forma.

As demais penalidades possíveis são também muito inferiores, em escala de dignidade, à prisão. A proibição de contratar com o poder público, em termos práticos, tem eficácia patrimonial, mas não significa "morte civil" ou algo extremado, pois a pessoa física ou jurídica continuará no mercado. Perda do cargo equivale a uma demissão por justa causa na iniciativa privada. Suspensão dos direitos políticos afasta o indivíduo de suas capacidades eleitorais ativas e passivas, mas isso está muito aquém de se privá-lo da liberdade.

Não se olvide que a produção de provas nesse tipo de investigação é complexa, porque normalmente estão elas sob o domínio dos investigados, e há sofisticadas técnicas de ocultação do aumento patrimonial injustificado. Outro fator que a dificulta, designadamente do elemento subjetivo, é a estrutura piramidal da administração pública, através da qual os procedimentos tramitam em uma série de instâncias, algumas colegiadas. Essa distância entre o acontecimento real e o órgão decisório, por vezes, enseja uma espécie de "cortina de fumaça" burocrática, sendo comumente alegado por gestores o desconhecimento do ilícito ocorrido na extremidade do procedimento administrativo.

Cogite-se, como hipótese, da responsabilidade da autoridade que homologa licitação deflagrada para aquisição de produto superfaturado. $O$ argumento recorrente é o desconhecimento dos valores de mercado, estimados por atos administrativos de subalternos. Nesse caso, crê-se que a circunstância objetiva de o ato de homologação servir como espécie de ratificação e atestado de lisura do procedimento já é indicativa do dolo: caso contrário, o ato de homologação se tornaria uma formalidade inútil, uma simples conferência de carimbos. $\mathrm{O}$

\footnotetext{
${ }^{10}$ No mesmo sentido: RE 1105822 Agr/SP, Rel. Min. Luiz Fux, j. em 22 de fevereiro de 2019.
} 
exemplo construído é abstrato, e, evidentemente num caso concreto reclamaria maiores pesquisas sobre as demais circunstâncias periféricas. Mas, serve para exibir um caso em que, no campo penal se reclamariam provas mais densas, ao passo que na ação de improbidade a aproximação da verdade poderia ser satisfeita com menores rigores.

A exclusão do método b.a.r.d. em processos sobre atos de improbidade justifica-se pelos custos das falsas improcedências. O Brasil ostenta índices alarmantes de corrupção, ocupando atualmente a $106^{\mathrm{a}}$ posição no índice de percepção de corrupção da Transparência Internacional ${ }^{11}$. Sancionar autores de atos de improbidade, condenando-os a ressarcir ao erário, afastando-os da vida pública e impondo-se outras sanções é o mínimo que se pode fazer para alterar-se a sensação de impunidade, além de se higienizar o ambiente político. Se a dúvida vai a favor do acusado no processo penal, porque não se pode arriscar sua liberdade, no processo civil deve haver maior elasticidade nessa compreensão, porque as penas previstas na LIA convergem para a restauração do erário e a tutela da moralidade administrativa.

Assim, entre custos e benefícios, o standard da prova prevalente - ou, no máximo, da prova clara e convincente caso se consiga distingui-lo justificadamente do primeiro - apresenta equilíbrio mais preciso em ações de improbidade, permitindo-se a obtenção de nível de prova dotado de probabilidade suficiente para se considerar comprovada a transgressão ao regime jurídico-administrativo.

\section{CONFISCO ALARGADO E MODELO DE VERIFICAÇÃO}

A Lei Federal n 13.964, de 24 de dezembro de 2019, incluiu o art. 91-A, no Código Penal, tratando-se de fruto do "pacote anticrime", proposto pelo Ministério da Justiça em fevereiro de 2019.

Seu conteúdo é um novo efeito da condenação pela prática de crimes cujo preceito secundário preveja pena superior a 6 anos de reclusão. Cuida-se da perda dos bens correspondentes à diferença entre o valor do patrimônio do condenado e aquele que seja compatível com o seu rendimento lícito, por alguns chamada de confisco alargado.

Trata-se de instituto já adotado em outros países, como Estados Unidos, Colômbia e Itália, e contemplado na Recomendação $\mathrm{n}^{\circ} 4$, do $\mathrm{FATF}^{12}$. A rigor, ampliou-se possibilidade já

\footnotetext{
${ }^{11}$ https://transparenciainternacional.org.br/ipc/

12 "Os países deveriam considerar a adoção de medidas que permitam a perda de tais produtos ou instrumentos (bens branqueados, instrumento e resultado de operação de lavagem ou de crime antecedente, bens equivalentes e bens aplicados em ações terroristas) sem necessidade de uma condenação penal prévia (perda de bens independente de condenação), bem como a adoção de medidas que exijam do presumível autor da infração a demonstração da
} 
prevista no art. $7^{\circ}$, inciso I, da Lei Federal $n^{\circ} 9.613 / 98$, pois o confisco alargado ali previsto era restrito às hipóteses de lavagem de dinheiro ou do crime antecedente.

A perda de bens reveste-se de absoluta propriedade para o enfraquecimento de associações criminosas, já que o ataque patrimonial lhes retira meios de financiamento das atividades. Além disso, a medida pretende demonstrar que o crime não valha a pena.

O texto prevê a decretação da perda de bens na sentença penal condenatória, e sua inovação consiste em não a restringir aos instrumentos ou produtos do crime, avançando sobre a parcela excedente àquilo cuja aquisição lícita pode ser comprovada. É prescindível provar que este ou aquele bem é fruto de um crime determinado.

São requisitos para a nova medida: condenação por infrações às quais a lei comine pena máxima superior a seis anos de reclusão; incompatibilidade entre os rendimentos lícitos do condenado e seu acervo patrimonial (art. 91-A, caput, do Código Penal), composto pelos bens de sua titularidade e por aqueles de que tenha o domínio e o benefício direto ou indireto, na data da infração penal ou recebidos posteriormente, assim como bens transferidos a terceiros a título gratuito ou mediante contraprestação irrisória, a partir do início da atividade criminal (parágrafo $1^{\circ}$ ). Ao condenado fica assegurada a possibilidade de demonstração de inexistência da incompatibilidade ou a procedência lícita do patrimônio (parágrafo $2^{\circ}$ ).

Questão intrigante é a respeito do standard probatório adequado a esse tipo de provimento. Um dos requisitos é a condenação pela prática de um crime cuja pena máxima prevista em lei seja superior a seis anos. Logicamente, a existência dos elementos do tipo de injusto (objetivos ou subjetivos) reclamam o critério da prova acima de dúvida razoável para se impor a condenação, não havendo dúvida nesse requisito.

Porém, como o confisco alargado atinge o patrimônio, e não a liberdade, o requisito da desproporcionalidade entre patrimônio e ganhos lícitos é aferível pela utilização do standard da probabilidade prevalente. $O$ fatiamento é perfeitamente justificável, porque a sentença pode ser dividida em capítulos identificáveis: um é a condenação pela prática do crime, com respectiva dosimetria da pena; outro trata da perda do patrimônio ilícito.

No capítulo da condenação, o juiz analisa os elementos do crime, com o rigor do modelo de prova acima de dúvida razoável. No capítulo da perda de bens, já não se trata sobre ação (ou omissão), tipicidade, ilicitude e culpabilidade: o exame judicial recairá sobre provas de conjunto patrimonial incompatível. Como a consequência é a extinção de domínio, e não a

origem lícita dos bens presumivelmente suscetíveis de perda, desde que esta exigência seja conforme com os princípios vigentes no respectivo direito interno". 
privação de liberdade, o standard apropriado é o da prova prevalente, pois, em última análise, se trata de consequência civil.

Os capítulos distintos da sentença são perceptíveis porque o caso é de cumulação de pedidos do Ministério Público, que está obrigado a apontar na denúncia a diferença apurada (art. 91, $\S 3^{\circ}$, do Código Penal). Cuidando-se de pedidos sucessivos (a perda de bens depende da procedência do pleito condenatório), há também cumulação de ações.

Assim, uma vez isoladas as subdivisões da sentença (condenação/perda de bens), a racionalidade do modelo de verificação é exatamente a mesma para as ações de improbidade, porque, em termos práticos, é como se houvesse duas sentenças condensadas em documento único. Observe-se que a perda de bens introduzida no Código Penal é similar àquela já prevista no art. $6^{\circ}$, da Lei Federal n ${ }^{\circ} 8.429 / 92$, no caso de condenação pela prática do ato de improbidade tipificado pelo art. $9^{\circ}$, inciso VII, da mesma lei.

Portanto, na valoração de provas sobre a desproporcionalidade do patrimônio do criminoso e seus ganhos lícitos, o juiz deverá utilizar o modelo da probabilidade prevalente para decidir sobre a possibilidade da perda de bens.

\section{PRECEDENTES DO CONSELHO DE ESTADO DA ITÁLIA}

O Conselho de Estado da Itália ${ }^{13}$ deparou-se com a controvérsia acerca do standard probatório adequado em processos nos quais se impugnam atos administrativos de interdição de estabelecimentos, por suspeitas de envolvimento com organizações de tipo mafioso.

A medida é prevista pelo Decreto Legislativo no 159, de 6 de setembro de 2011, que prevê o código de leis antimáfia e medidas de prevenção. Nos artigos 89-bis, 90 e 91, o código prevê a chamada informação antimáfia, outorgando ao prefeito da província poder para intervenção na gestão da empresa suspeita.

No julgamento do recurso 2286/2019, a Terceira Seção do Conselho de Estado apreciou impugnação de uma sociedade atuante no ramo hoteleiro, que recebeu a informazione antimafia a carattere interdittivo do prefeito da província de Reggio Calabria. A autoridade administrativa identificou indícios de associação entre a pessoa jurídica e organização criminosa, e então nomeou comissário extraordinário para a gestão temporária da empresa ${ }^{14}$.

\footnotetext{
${ }^{13}$ A Itália adota a dualidade de jurisdição, em que grande parte dos atos administrativos não se sujeitam ao controle do Poder Judiciário, mas sim da Justiça Administrativa. O Consiglio di Stato é, basicamente, o órgão de segundo grau da Justiça Administrativa.

${ }^{14}$ A sentença tem o número 06105/2019, e foi consultada no seguinte site, em 13/11/2019:
} 
Uma das teses levantadas pela recorrente foi a impossibilidade de se utilizar o modelo da probabilidade prevalente, mercê da gravidade da medida. $\mathrm{O}$ argumento foi rejeitado pelo Conselho de Estado, que reafirmou precedentes no sentido de que a autoridade administrativa pode se valer, para avaliação da existência de infiltração mafiosa, de elementos graves, precisos e concordantes, dotados de coerência e relevância. A Corte assentou que, em sua jurisprudência, é pacífico o entendimento de que o critério da prova prevalente é apropriado para se constatar a infiltração mafiosa. Confira-se:

\begin{abstract}
"O standard probatório subjacente à regra "mais provável do que não", ao exigir a verificação de probabilidade crucial, de fato, requer, no nível da taxatividade processual, mais provavelmente a hipótese de infiltração da máfia do que "todas as outras reunidas", na apreciação dos elementos circunstanciais colocados na base da decisão da prefeitura, que, portanto, se baseiam em limiar de coerência e significância dotado de uma credibilidade racional superior a qualquer outra explicação lógica alternativa, em que a existência de explicações divergentes, fornecidas com algum elemento concreto, implicaria uma dúvida razoável (Cons. St., seção III, 26 de setembro de 2017 4483), nesta matéria, não exigindo a apuração de uma responsabilidade que supere qualquer dúvida razoável, típica de casos criminais, nem podendo transferir para ela, indevidamente, as categorias típicas de lei e julgamento criminal, isso frustraria irreparavelmente sua função preventiva." ${ }^{15}$
\end{abstract}

O precedente mostra, com propriedade, que é descabido o recurso ao modelo da prova acima de dúvida razoável ao se tratar de medidas administrativas, ainda que se trate de algo bastante invasivo, como a intervenção na administração de sociedade empresária.

Medida dessa intensidade mostra-se da mesma estatura das sanções previstas pela LIA, e se equipara ao confisco alargado, pois há o reconhecimento incidental de indícios de associação criminosa. Assim, o Direito comparado traz mostras de exemplo exitoso, em que o standard probatório utilizado para se dar concretude ao ordenamento foi o da probabilidade prevalente.

\footnotetext{
https://www.giustizia-

amministrativa.it/web/guest/dcsnprr?p_p_id=GaSearch_INSTANCE_2NDgCF3zWBwk\&p_p_state=normal\&p_ p_mode=view\&_GaSearch_INSTANCE_2NDgCF3zWBwk_javax.portlet.action=searchProvvedimenti\&p_auth $=\mathrm{bVHbK} 8 \mathrm{rE} \& \mathrm{p} \_\mathrm{p} \_$lifecycle $=0$

${ }^{15}$ No original: "Lo standard probatorio sotteso alla regola del "più probabile che non", nel richiedere la verifica della c.d. probabilità cruciale, impone infatti di ritenere, sul piano della tassatività processuale, più probabile l'ipotesi dell'infiltrazione mafiosa rispetto a "tutte le altre messe insieme", nell'apprezzamento degli elementi indiziari posti a base del provvedimento prefettizio, che attingono perciò una soglia di coerenza e significatività dotata di una credibilità razionale superiore a qualsivoglia altra alternativa spiegazione logica, laddove l'esistenza di spiegazioni divergenti, fornite di un qualche elemento concreto, implicherebbe un ragionevole dubbio (Cons. St., sez. III, 26 settembre 2017, n. 4483), non richiedendosi infatti, in questa materia, l'accertamento di una responsabilità che superi qualsivoglia ragionevole dubbio, tipico delle istanze penali, né potendo quindi traslarsi ad essa, impropriamente, le categorie tipiche del diritto e del processo penale, che ne frustrerebbero irrimediabilmente la funzione preventiva."
} 


\section{CONCLUSÃO}

A pesquisa realizada permitiu identificar ampla variedade de critérios norteadores para verificação do grau de suficiência da prova para a que a sentença reconhece que determinado fato está comprovado.

Embora a verdade seja uma, sua relatividade e as limitações do conhecimento humano impõem que os standards probatórios sejam diferentes conforme o tipo de relação processual. A eleição de um modelo de verificação é política e se destina à distribuição dos riscos de erros entre as partes, devendo ser orientada, portanto, pelo bem jurídico subjacente à relação processual, pelos custos das falsas absolvições (improcedências) e pela dificuldade na obtenção da prova em determinada constelação de casos.

A partir dessas premissas e, levando-se em conta que as sanções pela prática de atos de improbidade administrativa e o confisco alargado não atingem a liberdade do indivíduo, mas bens jurídicos de estatura inferior, o resultado obtido é pela adequação do standard probatório da probabilidade prevalente na fundamentação da sentença (ou de seu capítulo) que decide a respeito desses institutos.

\section{REFERÊNCIAS:}

BALTAZAR JUNIOR, José Roberto. Standards probatórios no processo penal. Revista da Associação dos Juízes Federais do Rio Grande do Sul, Porto Alegre, vol. 4, p. 161-185, nov. 2007. Disponível em: https://www.ajufergs.org.br/arquivos-revista/4/revista4.pdf. Acesso em: 18 nov. 2019.

BERTONCINI, Mateus Eduardo Siqueira Nunes; GARBIN, Maurício Augusto. CIDADANIA, PRINCÍPIO DA RAZOABILIDADE E O PROBLEMA DO ATO DE IMPROBIDADE ADMINISTRATIVA CULPOSO. Revista Juridica, [S.1.], v. 2, n. 43, p. 93 - 113, fev. 2017. ISSN 2316-753X.

Disponível

em: <http://revista.unicuritiba.edu.br/index.php/RevJur/article/view/1818/1195>. Acesso em: 20 abr. 2020. doi:http://dx.doi.org/10.21902/revistajur.2316-753X.v2i43.1818.

BRASIL. Decreto-lei n. 3.689, de 3 de outubro de 1941. Código de Processo Penal.

BRASIL. Decreto-lei n. 2.848, de 7 de dezembro de 1940. Código Penal.

BRASIL. Lei Federal no 8.429, de 2 de junho de 1992. Dispõe sobre as sanções aplicáveis aos agentes públicos nos casos de enriquecimento ilícito no exercício de mandato, cargo, empregou ou função na administração pública direta, indireta ou fundacional e dá outras providências.

BRASIL. Lei Federal $\mathrm{n}^{\circ}$ 9.605, de 12 de fevereiro de 1998. Dispõe sobre as sanções penais e administrativas derivadas de condutas e atividades lesivas ao meio ambiente, e dá outras providências. 
BRASIL. Lei Federal no 9.613, de 3 de março de 1998. Dispõe sobre os crimes de "lavagem" ou ocultação de bens, direitos e valores; a prevenção da utilização do sistema financeiro para os ilícitos previstos nessa lei; cria o Conselho de Controle de Atividades Financeiras - COAF, e dá outras providências.

BRASIL. Lei Federal no 11.343, de 23 de agosto de 2006. Institui o Sistema Nacional de Políticas Públicas sobre Drogas - Sisnad; prescreve medidas para prevenção do uso indevido, atenção e reinserção social de usuários e dependentes de drogas; estabelece normas para repressão à produção não autorizada e ao tráfico ilícito de drogas; define crimes e dá outras providências.

BRASIL. Tribunal de Justiça do Estado do Paraná. 4a Câmara Cível. Apelação Cível n. 1505843-6. Paranavaí. Relatora: Desembargadora Regina Afonso Portes. Julgado em 23.8.2016

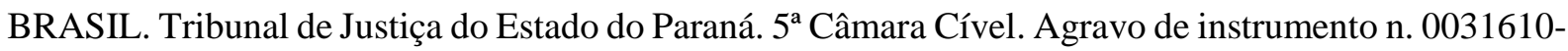
04.2019.8.16.0000. Londrina. Relator: Desembargador Nilson Mizuta. Julgado em 22.10.2019.

BRASIL. Supremo Tribunal Federal. Plenário. ADI n. 2797. Relator: Ministro Sepúlveda Pertence. Julgado em 15.9.2005.

BRASIL. Supremo Tribunal Federal. $1^{a}$ Turma. Ação Penal n. 580. Relatora: Ministra Rosa Weber. Julgado em 13.12.2016.

BRASIL. Supremo Tribunal Federal. $1^{a}$ Turma. Ação Penal n. 694. Relatora: Ministra Rosa Weber. Julgado em 2.5.2017.

BRASIL. Supremo Tribunal Federal. $1^{a}$ Turma. Ação Penal n. 676. Relatora: Ministra Rosa Weber. Julgado em 17.10.2017.

BRASIL. Supremo Tribunal Federal. $1^{\mathrm{a}}$ Turma. Agravo regimental no recurso extraordinário n. 1105822. Relator: Ministro Luiz Fux. Julgado em 22.2.2019.

BRASIL. Superior Tribunal de Justiça. Corte Especial. Ação Penal n. 593/MT. Relator: Ministro Humberto Martins. Julgado em 17.12.2012.

CAMBI, Eduardo et al. Curso de Processo Civil completo (livro eletrônico). São Paulo: Thomson Reuters do Brasil, 2 ed em e-book baseada na $2^{\mathrm{a}}$ ed. Impressa.

CARPES, Artur Thompsen. Ônus da prova no novo CPC (livro eletrônico): do estático ao dinâmico. São Paulo: Editora Revista dos Tribunais, 2017, parte I.

FERRER BELTRÁN, Jordi. TUZET, Giovani. Sulla necessità degli standard di prova per la giustificazione dele decisioni giudiziali. Diritto \& Questioni Pubbliche, Palermo, Vol.18-2, p. 455-472, dez. 2018. Disponível em: http://www.dirittoequestionipubbliche.org/page/2018_n18-2/18ratio_FerrerBeltran-Tuzet.pdf. Acesso em: 18 nov. 2019.

GOMES FILHO, Antônio Magalhães. A motivação das decisões penais. 1 ed. São Paulo: Editora Revista dos Tribunais, 2014.

ITÁLIA. Conselho de Estado. 3ª Seção. Recurso n. 2286 de 2019. Sentença n. 06105/2019. Relator Massimiliano Noccelli. Julgado em 25.7.2019. Disponível em: https://www.giustiziaamministrativa.it/web/guest/dcsnprr?p_p_id=GaSearch_INSTANCE_2NDgCF3zWBwk\&p_p_state=n ormal\&p_p_mode=view\&_GaSearch_INSTANCE_2NDgCF3zWBwk_javax.portlet.action=searchPro vvedimenti\&p_auth=bVHbK8rE\&p_p_lifecycle=0. Acesso em 13.11.2019. 
KNIJNIK, Danilo. Os "standards" do convencimento judicial: paradigmas para o seu possível controle, Revista Forense, Rio de Janeiro, n. 353, jan.-fev. 2001. Disponível em: abdpc.org.br/abdpc/artigos/Danilo\%20Knijnik\%20-\%20formatado.pdf. Acesso em: 18 nov. 2019.

LUCON, Paulo Henrique dos Santos. A prova na ação de improbidade administrativa. In: OLIVEIRA NETO. Olavo de; MEDEIROS NETO, Elias Marques de; CASTRO LOPES, Ricardo Augusto de (coordo). A prova no direito processual civil: estudos em homenagem ao professor João Batista Lopes. 1 ed. São Paulo: Editora Verbatim, 2013. P. 540.

MARINONI, Luiz Guilherme. ARENHART, Sérgio Cruz. Comentários ao código de processo civil, v. 5: do processo de conhecimento, arts. 332 a 341, tomo 1. 2 ed. São Paulo: Editora Revista dos Tribunais, 2005.

MARQUeS, José Frederico. Elementos de Direito Processual Penal. Vol. II. 2 ed. Campinas: Millennium, 2000.

MORO, Sergio Fernando. Direitos fundamentais contra o crime. In: CLÈVE, Clemerson Merlin (coord). Direito Constitucional brasileiro: Teoria da Constituição e direitos fundamentais. São Paulo: RT, 2014, vol. 1, p. 559-581,

MORO, Sergio Fernando. Crime de lavagem de dinheiro. São Paulo: Editora Saraiva, 2010.

NERY JUNIOR, Nelson. ANDRADE NERY, Rosa Maria. Comentários ao Código de Processo Civil. $5^{\text {a }}$ ed. São Paulo: Editora Revista dos Tribunais, 2001.

NERY JUNIOR, Nelson. ANDRADE NERY, Rosa Maria. Comentários ao Código de Processo Civil. São Paulo: Editora Revista dos Tribunais, 2015.

ROCHA, Mauro Sérgio. Aplicação direta dos princípios constitucionais: controle de constitucionalidade das decisões judiciais. Porto Alegre: Sérgio Antonio Fabris Ed., 2016.

TARUFFO, Michele. Ensaios sobre o processo civil: escritos sobre processo e justiça civil. Organizador e revisor das traduções Darci Guimarães Ribeiro. Porto Alegre: Livraria do Advogado, 2017.

TARUFFO. Michele. Ermeneutica, prova e decisione. Revista Brasileira de Direito Processual Penal, Porto Alegre, vol. 4, n. 1, p 129-148, jan-abr. 2018. 